\title{
Self-perceived need for dental treatment and related factors. A cross-sectional population-based study
}

\section{Luciana Freitas Gomes e SILVA ${ }^{(a)}$ Erika Barbara Abreu Fonseca THOMAZ (b) \\ Heloiza Viana FREITAS(b) \\ Cecília Cláudia Costa RIBEIRO(c) \\ Alex Luiz Pozzobon PEREIRA(c) \\ Cláudia Maria Coelho ALVES(c)}

\footnotetext{
(a) Universidade CEUMA - UNICEUMA, School of Dentistry, Graduate Program in Dentistry, São Luiz, MA, Brazil.

(b) Universidade Federal do Maranhão -UFMA, Graduate Program in Collective Health, São Luiz, MA, Brazil.

(c) Universidade Federal do Maranhão - UFMA, School of Dentistry, Graduate Program in Dentistry, São Luiz, MA, Brazil.
}

Declaration of Interests: The authors certify that they have no commercial or associative interest that represents a conflict of interest in connection with the manuscript.

\section{Corresponding Author:}

Luciana Freitas Gomes e Silva

E-mail: lucianafgs@gmail.com

DOI: 10.1590/1807-3107BOR-2016.vol30.0055

Submitted: Sep 25, 2015

Accept for publication: Dec 14, 2015

Last revision: Feb 26, 2016
Abstract: This study compared adolescents' self-perceived need for orthodontic treatment with the normative need for such treatment and investigated associations between socioeconomic and demographic variables and self-perceptions of dental malocclusion. This cross-sectional study involved 1015 schoolchildren aged 12-15 years in São Luís, Maranhão, Brazil. The following data were collected using a questionnaire and an orthodontic examination card: demographic and identifying data, socioeconomic data, educational levels of family, household income, economic classification criteria, and self-reported skin color behavioral data, and oral health data. Normative occlusal condition was examined using the Angle classification and Dental Aesthetic Index (DAI). Data were analyzed using the chi-squared test (to analyze differences in the frequency distribuition of qualitative variables) and Poisson regression (to stimate associations between the perceived need of orthodontic treatment and study covariates), with a 5\% significance level. Schoolchildren's self-perceived need for orthodontic treatment was associated with sex $(\mathrm{p}=0.022)$ and the normative need for treatment $(p=0.004)$. Among socioeconomic, demographic, and oral health variables, only sex [prevalence ratio $(\mathrm{PR})=1.15 ; 95 \%$ confidence interval $(95 \% \mathrm{CI})=1.04-1.28 ; \mathrm{p}=0.009]$ and the normative need for orthodontic treatment $(\mathrm{PR}=1.19 ; 95 \% \mathrm{CI}=1.08-1.32 ; \mathrm{p}<0.001)$ were associated with the perception of malocclusion, with female adolescents reporting a greater need for orthodontic treatment. Female adolescents seems to be more sensitive to oral health problems. The results suggest that the DAI score might reflect a self-perceived need for orthodontic treatment and the Angle classification might overestimate the orthodontic treatment need.

Keywords: Malocclusion; Adolescent; Index of Orthodontic Treatment Need; Self Concept.

\section{Introduction}

The worldwide prevalence of malocclusion is considered to be high, as exemplified by studies performed in Spain (58.6\%), Iran (77.1\%), and Italy (93\%). ${ }^{1,2,3}$ In Brazil, the malocclusion rate is 37.6\% among 12-year-old children and 35.6\% among children aged $15-19$ years. ${ }^{4}$ In the Brazilian states of Minas Gerais, Paraíba, and São Paulo, the malocclusion rate ranges from $62 \%$ to $66.75 \%$ among children aged $12-18$ years. ${ }^{5,6}$ Due to high 
prevalence in various populations of the world, the malocclusions started to be targeted of researches. ${ }^{7}$

Traditionally, determination of the need for dental treatment is based on normative measures that do not take into account patients' expectations or perceptions of what should lead them to seek treatment. For example, they do not know the degree to which malocclusion can negatively affect their day-to-day lives via functional limitations and impacts on psychosocial well-being. The increased need for orthodontic treatment, reported over the recent years, cannot be explained only by oral health status. I can be rather associated mainly to social, physical and psychological reasons. ${ }^{8}$

Unlike those of many other countries, the population of Brazil is characterized by a large amount of ethnic intermixture. Orthodontists appear to be in consensus that parameters constituting morphological normality can vary among ethnic groups or populations from different geographic regions. ${ }^{9}$ Together with these ethnic aspects, socioeconomic factors must be considered in the examination of occlusion; this aspect of orthodontics should be studied within a social context, given the importance not only of the physical consequences of poor development, but also its negative impact on social well-being. ${ }^{5,10}$

With the development of more comfortable and esthetic orthodontic devices, improved treatment, and more widespread access to information, patients' perceptions about whether their occlusion is cosmetically acceptable have changed. Patients increasingly recognize the availability of orthodontic treatment to improve the appearance of their teeth and/or face. ${ }^{11}$ However, there is a lack in this field of research once the number of such surveys is still limited. Few studies ${ }^{12,13,14}$ have evaluated the relationship between the normative need for orthodontic treatment and patients' perceived need or associated factors. A study conducted in southern Italy found that $59.5 \%$ of 546 schoolchildren aged 11-15 years (including those with histories of orthodontic device use) had malocclusion requiring normative orthodontic treatment, although only 9.5\% perceived the need for such treatment ${ }^{12}$ while $78 \%$ of 403 Brazilian adolescents aged $14-18$ years perceived the need for orthodontic treatment, although only $23 \%$ showed a normative need; $>2 \mathrm{~mm}$ crowding of the maxillary anterior teeth was a factor associated with this perception. ${ }^{13}$ In another study involving 386 children aged 11-16 years in Belgium who presented at a hospital's orthodontics department, the association between self-perceived and normative needs for orthodontic treatment was weak. ${ }^{14}$

Thus, traditional means of evaluating malocclusion have certain limitations and may limit the amount of orthodontic treatment provided, in that they do not appear to adequately account for patients' self-perceived need for treatment. This, arguably, may lead to denial of treatment to children with a genuine socio-dental need. As a result, a method of incorporating children' values into an evaluation of treatment need is required..$^{15}$

This study was conducted to compare self-perceived and normative needs for orthodontic treatment and to investigate associations between socioeconomic and demographic variables and the self-perception of dental malocclusion among adolescents in Brazil.

\section{Methodology}

\section{Study design and sample}

This cross-sectional study was based on a representative sample of male and female schoolchildren aged 12-15 years in São Luís, MA, Brazil. This age range was selected following WHO's recommendation for epidemiological surveys of main changes in the mouth, ${ }^{16}$ and because the permanent dentition has been established by the age of 12 years.

Cluster sampling was conducted in two stages. We selected schools (primary sampling units) and students (secondary sampling units) using the lists of schools available at the Instituto Nacional de Estudos e Pesquisas Educacionais Anísio Teixeira - INEP/Ministério da Educação - MEC and Conselho de Educação of the City of São Luís, MA, as well as the list of students aged 12-15 years enrolled in the city's public and private school networks available at each school selected. The number of students selected from each school was proportional to the size of the school. 
Eligible participants were students regularly enrolled in $5^{\text {th }}-9^{\text {th }}$ grades in the city of São Luís, MA who were aged 12-15 years at the time of examination and had received no prior orthodontic treatment. Schoolchildren with mental problems according data school, those lacking first molars, those who refused to participate in the study, and those who were absent from school during the evaluators' three visits were excluded.

We estimated that a sample of 346 schoolchildren would have a $90 \%$ power and $95 \%$ confidence level to identify significant prevalence ratios (PR) exceeding 1.5. We assumed a malocclusion rate of $35.6 \%^{4}$ and a 1:1 ratio of exposed to unexposed to the different exploratory variables of the study. Considering the design effect (stratified cluster sample) of the study's complex sample equal to 2.0, the estimated minimum sample size was 692 schoolchildren. We maintained the proportion of children aged 12-15 years observed in the population using estimates from the Instituto Brasileiro de Geografia e Estatística - IBGE ${ }^{17}$ as a reference. Foreseeing the possibility of missing data, losses, and the need for stratification, we increased this number by $30 \%$ to a total minimum sample of 900 adolescents.

\section{Data collection}

Two collection teams, each consisting of an interviewer/note-taker and an examiner (orthodontist), were provided with a manual containing detailed information about the questionnaire items and orthodontic examination, and received training in the application of the research instruments and clinical examination. Diagnostic (inter- and intra-examiner) reproducibility was estimated using kappa and intraclass correlation tests, with values $\geq 0.7$ considered to be acceptable. Patients examined during the training phase were not included in the study sample.

The following data were collected according to the $\mathrm{WHO}^{\prime}$ 's recommendation $\mathrm{s}^{16}$ using a questionnaire and an orthodontic examination card: demographic and identifying data (e.g., subject's name, date of birth, sex, home address, telephone number, and date of interview), socioeconomic data [e.g., school name and type (public/private), educational levels of the subject's mother and head of family, household income, economic classification criteria, ${ }^{18}$ and self-reported skin color] behavioral data (e.g., subject's perception of the need for orthodontic treatment), and oral health data [e.g., occlusal conditions according to the Angle classification ${ }^{19}$ and Dental Aesthetic Index (DAI). ${ }^{20}$

The Angle classification ${ }^{19}$ it has been widely used as a qualitative epidemiological tool for malocclusion evaluation but describes only the existence or absence of malocclusion. The $\mathrm{DAI}^{20}$ is a quantitative index that was developed to study and measure malocclusion. This index has provided useful information on treatment need but did not give accurate information regarding prevalence of specific malocclusion. To gain more accurate information with regards to prevalence of malocclusion and treatment need, more than one method need to be used.

Molar relationships were recorded according to the Angle classification as Class I, Class II division 1 or 2 , or Class III. ${ }^{19}$ For the purposes of analysis, this variable was later categorized as normal, Class I, Class II, and Class III.

As recommended by the $\mathrm{WHO}^{16}$ the DAI was used to evaluate the rate and severity of malocclusion and the normative need for orthodontic treatment. This universally accepted index can be used to evaluate the need for orthodontic treatment and prioritize the provision of orthodontic care in public health programs. ${ }^{17,20}$ In this study, subjects with DAI grades 1 (<25; no need) and 2 (26-30; elective need) were considered to have no normative need for treatment, whereas subjects with DAI grades 3 (31-35; highly desirable need) and 4 ( $\geq 36$; mandatory need) were considered to have a normative need for orthodontic treatment.

These oral examinations were made in the school, with natural light. DAI measurements were made according to WHO recommendations. ${ }^{16} \mathrm{But}$, in order to make the orthodontic measurements most sensitive, we used an orthodontic tape (1-mm diameter, 6-cm length, Morelli, Sorocaba, Brazil) and an adapted silicone cursor (Angelus, Londrina, Brazil). Besides, the measurements (in millimeters) were made using an endodontic ruler (Angelus, Brazil). 
The outcome of interest in this study (self-perceived need for orthodontic treatment) was evaluated using the student's answer to the question: "How much do you think you need to make an orthodontic treatment?" Response was given on a scale ranging from 1 to 10 , with responses $\geq 6$ considered to reflect perceived need for orthodontic treatment.

\section{Statistical analysis}

Data were entered into an Excel spreadsheet (Microsoft Corp., College Station, USA) and analyzed using Stata software (version 11.0 for Windows; Stata Corp., College Station, USA). Initial descriptive analysis involved the calculation of absolute and relative frequencies with 95\% confidence intervals (95\%CI). Differences in the frequency distributions of qualitative (categorical) variables were analyzed using the chi-squared test. Associations between the perceived need for orthodontic treatment and study covariates were estimated based on PR and 95\%CI using Poisson regression analysis with a hierarchical

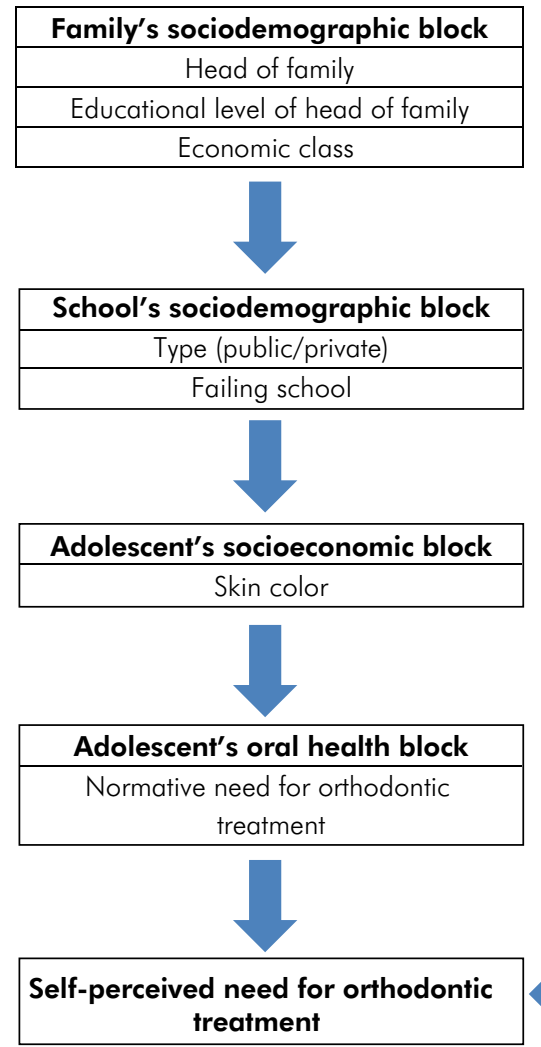

approach. We built a theoretical model (Figure) with four hierarchical levels. $p$-value $<0.20$ in the univariate analysis was used as a criterion for selecting variables to be tested in the multivariate model. Only were kept in the multivariate model variables with $p$-value less than $10 \%$. The significance level adopted for all analyses was $5 \%(\mathrm{p}<0.05)$.

\section{Ethical considerations}

The Research Ethics Committee of the hospital of the Universidade Federal do Maranhão - UFMA approved this study (no. 2429/2010-10). We obtained consent from the Conselho Estadual de Educação and school directors, and written informed consent from participants' parents guardians.

\section{Results}

The sample consisted of 1015 schoolchildren aged 12-15 years (503 male; 512 female), examined in 30 schools (19 public, 11 private). The rate of malocclusion, according to the Angle classification, was 94.7\%; Class I

Level 1: distal
Level 3: intermediate

Level 4: proximal

\begin{tabular}{|l|}
\hline Adolescent's demographic block \\
\hline Sex \\
\hline Age \\
\hline
\end{tabular}

Figure. Theoretical model of the sociodemographic determination of adolescents' oral health. 
malocclusion was most common (56.3\%), followed by Classes II (33\%) and III (5.4\%). Only 5.3\% of children had normal occlusion. The rate of normative need for orthodontic treatment was $44.8 \%$, whereas $60.5 \%$ of participants perceived the need for treatment.

Among socioeconomic, demographic, and oral health variables, only sex $(p=0.009)$ and the normative need for orthodontic treatment $(p<0.001)$ were associated with the perception of malocclusion. Female adolescents reported a $15 \%$ greater need than males for orthodontic treatment ( $\mathrm{PR}=1.15 ; 95 \% \mathrm{CI}: 1.04-1.28$ ), and $19 \%$ of schoolchildren who reported subjective need had also normative need for orthodontic treatment (PR = 1.19; 95\%CI: 1.08-1.32), (Table).

\section{Discussion}

Dissatisfaction with appearance is the main reason that people seek orthodontic treatment. ${ }^{10}$ In this study, adolescents' self-perceived need for orthodontic treatment exceeded the normative need for such treatment, emphasizing the importance of these aesthetic aspects to personal satisfaction. The study findings are similar to those of other studies conducted in Brazil, 5,13,21 which have documented greater self-perceived than normative need for treatment; the need for orthodontic treatment could not be justified by objective criteria in about half of adolescents. This high prevalence obtained in Brazil may be related to the relationship between the self-perceived need for orthodontic treatment and a person's desire to demonstrate his or her high socioeconomic standing or to be fashionable.,22

So, although some authors have reported that normative criteria for orthodontic treatment overestimate the prevalence of occlusal problems compared with adolescents' perceptions, ${ }^{23}$ our study found the opposite to be true. Studies performed in the United Kingdom, ${ }^{23}$ Nigeria, ${ }^{24}$ and Croatia ${ }^{25}$ have shown low levels of self-perceived need for orthodontic treatment $(6 \%, 17.5 \%$, and $24,2 \%$, respectively), suggesting the existences of differences related to ethnic and cultural factors. ${ }^{9}$ Conceptions of beauty vary widely among cultures, with a beautiful body associated with intelligence and high income in Western societies; this factor explains why Brazilians, especially adolescents, pay so much attention to cosmetic factors. ${ }^{26}$
We have found a correlation between normative and self-perceived needs for orthodontic treatment. However, the literature contains discrepancies regarding to this association. Nobile et al. ${ }^{12}$ found no such association in an Italian sample, and Ghijselings et al. ${ }^{14}$ found a significant, but weak, correlation among subjects in Belgium. This association is plausible, since orthodontic problems have repercussions on aesthetics and orofacial functions. ${ }^{27,28}$ Thus, it is expected that they are perceived by people.

In this study, only sex was associated with the perception of malocclusion, with female adolescents reporting a greater need for orthodontic treatment. Other studies have also found that women are more self-critical in terms of the self-perception of malocclusion and that they have more pronounced self-esteem issues than men. ${ }^{21,28,29}$ One possible explanation for these findings is that women are more preoccupied with health and appearance than men, and that they feel more upset by and are more conscious of the impact of oral health on their facial appearance and quality of life. ${ }^{29,30}$ From childhood, females use oral health services more frequently than males. ${ }^{31}$ These factors may make women more sensitive than men to oral health problems.

The high rate of malocclusion, according to the Angle classification, observed in our study is similar to that reported in Latin adolescents in the United States (93\%), ${ }^{32}$ but higher than those found among Iranian adolescents $(77.1 \%)^{2}$ and in other studies of adolescents in Brazil (62-83\%). ${ }^{5,33}$ These differences are likely related to sample selection, evaluation methods, and diagnostic criteria, as well as ethnic and age differences among samples. Findings must thus be compared with caution. However, all studies have documented high rates of malocclusion in adolescents.

Our finding on rate of malocclusion according Angle classification is in agreement with the results of several previous studies., ${ }^{2,634}$ Other studies have found that Class $\mathrm{II}^{35}$ or Class $\mathrm{III}^{36}$ was most common, but they involved patients seeking dental treatment at universities or hospitals, potentially introducing selection bias leading to overestimation of the rates of severe forms of malocclusion. 
Table. Distribution and association of sociodemographic and oral health variables with Brazilian adolescents' self-perceived need for orthodontic treatment.

\begin{tabular}{|c|c|c|c|c|c|c|c|c|c|}
\hline \multirow{3}{*}{ Variable } & & & & & \multicolumn{5}{|c|}{ Self-perceived need for orthodontic treatment } \\
\hline & \multicolumn{2}{|c|}{ No } & \multicolumn{2}{|c|}{ Yes } & \multirow[t]{2}{*}{$\mathrm{p}$} & \multicolumn{2}{|c|}{ Unadjusted PR } & \multicolumn{2}{|c|}{ Adjusted PR } \\
\hline & $\mathrm{n}$ & $\%$ & $\mathrm{n}$ & $\%$ & & $(95 \% \mathrm{Cl})$ & $p$ & $(95 \% \mathrm{Cl})$ & $p$ \\
\hline \multicolumn{10}{|c|}{ Families' sociodemographic variables } \\
\hline Head of family & & & & & 0.423 & & & & \\
\hline Mother & 233 & 57.96 & 336 & 54.82 & & 1.00 & & & \\
\hline Father & 126 & 31.59 & 218 & 35.56 & & $1.07(0.95-1.20)$ & 0.253 & - & - \\
\hline Other & 42 & 10.45 & 59 & 9.62 & & $0.99(0.84-1.16)$ & 0.893 & - & - \\
\hline \multicolumn{5}{|c|}{ Educational level of head of family } & 0.759 & & & & \\
\hline $\begin{array}{l}\text { Elementary School } \\
\text { incomplete }\end{array}$ & 59 & 14.68 & 87 & 14.19 & & 1.00 & & & \\
\hline $\begin{array}{l}\text { Elementary School } \\
\text { complete }\end{array}$ & 97 & 24.13 & 148 & 24.19 & & $1.01(0.83-1.24)$ & 0.889 & - & - \\
\hline High School complete & 164 & 40.80 & 267 & 43.56 & & $1.04(0.87-1.24)$ & 0.658 & - & - \\
\hline Bachelor's complete & 82 & 20.40 & 111 & 18.11 & & $0.97(0.81-1.15)$ & 0.681 & - & - \\
\hline Economic class (ABEP) & & & & & 0.259 & & & & \\
\hline$A, B$ & 138 & 34.33 & 186 & 30.34 & & 1.00 & & & \\
\hline C & 217 & 53.98 & 366 & 59.71 & & $1.09(0.98-1.22)$ & 0.111 & $1.09(0.98-1.21)^{1}$ & $0.100^{1}$ \\
\hline$D, E$ & 47 & 11.69 & 61 & 9.95 & & $0.98(0.77-1.25)$ & 0.890 & $0.98(0.78-1.23)^{1}$ & $0.846^{1}$ \\
\hline \multicolumn{10}{|c|}{ Schools' sociodemographic variables } \\
\hline Administrative responsibilit & & & & & 0.941 & & & & \\
\hline Public & 304 & 75.62 & 462 & 75.37 & & 1.00 & & & \\
\hline Private & 98 & 24.38 & 151 & 24.63 & & $1.00(0.87-1.17)$ & 0.941 & - & - \\
\hline Failing school & & & & & 0.263 & & & & \\
\hline No & 44 & 10.95 & 82 & 13.78 & & 1.00 & & & \\
\hline Yes & 358 & 89.05 & 531 & 86.62 & & $0.92(0.79-1.06)$ & 0.245 & - & - \\
\hline \multicolumn{10}{|c|}{ Adolescents' sociodemographic variables } \\
\hline Skin color & & & & & 0.340 & & & & \\
\hline White & 110 & 27.36 & 139 & 22.68 & & 1.00 & & 1.00 & \\
\hline Brown & 239 & 59.45 & 384 & 62.64 & & $1.10(0.97-1.25)$ & 0.119 & $1.10(0.98-1.25)^{2}$ & $0.113^{2}$ \\
\hline Black & 53 & 13.18 & 90 & 14.68 & & $1.13(0.93-1.36)$ & 0.202 & $1.12(0.94-1.34)^{2}$ & $0.193^{2}$ \\
\hline Sex & & & & & $0.022^{*}$ & & & & \\
\hline Male & 219 & 54.48 & 284 & 46.33 & & 1.00 & & 1.00 & \\
\hline Female & 183 & 45.52 & 329 & 53.67 & & $1.14(1.02-1.27)$ & 0.019 & $1.15(1.04-1.28)^{2}$ & $0.009^{2 *}$ \\
\hline Age (years) & & & & & 0.349 & & & & \\
\hline 12 & 98 & 24.38 & 127 & 20.72 & & 1.00 & & 1.00 & \\
\hline 13 & 116 & 28.86 & 201 & 32.79 & & $1.12(0.97-1.30)$ & 0.121 & $1.13(0.97-1.32)^{2}$ & $0.103^{2}$ \\
\hline 14 & 96 & 23.88 & 130 & 21.21 & & $1.02(0.86-1.20)$ & 0.816 & $1.01(0.85-1.19)^{2}$ & $0.920^{2}$ \\
\hline 15 & 92 & 22.89 & 155 & 25.29 & & $1.11(0.94-1.32)$ & 0.214 & $1.11(0.94-1.31)^{2}$ & $0.220^{2}$ \\
\hline NNOT & & & & & $0.004^{*}$ & & & & \\
\hline No & 245 & 60.95 & 316 & 51.55 & & 1.00 & & 1.00 & \\
\hline Yes & 157 & 39.05 & 297 & 48.45 & & $1.16(1.05-1.28)$ & $0.004^{*}$ & $1.19(1.08-1.32)^{3}$ & $0.001^{3 *}$ \\
\hline
\end{tabular}

PR: prevalence ratio; ABEP: Associação Brasileira de Empresas de Pesquisa; NNOT: normative need for orthodontic treatment.

${ }^{*} p<0.05$.

'Adjusted for sex and age.

${ }^{2}$ Adjusted for economic class and variables from the same block.

${ }^{3}$ Adjusted for economic class, skin color, sex, and age.

(--) Variable not selected for adjusted analysis $(p>0.20)$. 
Normative clinical criteria indicated that nearly half of our population required orthodontic treatment, similar to the results reported by Dawoodbhoy et al. ${ }^{37}$ (47.1\%). Marques et al. ${ }^{5}$ and Agou et al. ${ }^{38}$ reported higher rates $(52.3 \%$ and $64.4 \%$, respectively), whereas other studies ${ }^{1,6,13,21}$ have documented lower rates ranging from $21.1 \%{ }^{1}$ to $26.42 \% .{ }^{21}$ All of these authors used the DAI to evaluate the need for orthodontic treatment in adolescents; differences in results may arise from the use of different cutoff criteria along the DAI scale (elective, highly desirable, or mandatory need for treatment). The disadvantages of the DAI include the inability to evaluate overall occlusal characteristics (i.e., dental, bone, soft-tissue, and stomatognathic conditions) using this tool. However, it has the advantages of simplicity, ease of use, and less requirement for professional knowledge of occlusal characteristics than other available indexes. ${ }^{39}$

Given that Brazil's Ministério da Saúde covers the costs of oral examinations (leading to diagnosis of malocclusion and determination of treatment need) and orthodontic/orthopedic devices, patients' treatment priorities also need to be assessed. ${ }^{5}$ The adoption of subjective criteria applied together with the DAI may help set priorities for orthodontic care, becoming evident that a method of assessing orthodontic need requires the integration of a normative clinical measure with a patientbased indicator of the adolescent's feelings and/or

\section{References}

1. Baca-Garcia A, Bravo M, Baca P, Baca A, Junco P. Malocclusions and orthodontic treatment needs in a group of Spanish adolescents using the Dental Aesthetic Index. Int Dent J. 2004;54(3):138-42. doi:10.1111/j.1875-595X.2004.tb00269.x

2. Borzabadi-Farahani A, Borzabadi-Farahani A, Eslamipour F. Malocclusion and occlusal traits in an urban Iranian population. An epidemiological study of 11- to 14-year-old children. Eur J Orthod. 2009;31(5):477-84. doi:10.1093/ejo/cjp031

3. Ciuffolo F, Manzoli L, D'Attilio M, Tecco S, Muratore F, Festa F, et al. Prevalence and distribution by gender of occlusal characteristics in a sample of Italian secondary impacts relating to oral functioning .and appearance, as well as with measures of the adolescent's oral health-related behaviour. ${ }^{40}$ Then, for complete assessment, it is suggested to include evaluation of the impact of malocclusion on quality of life.

This study's strengths include the large sample of schoolchildren that was representative of the adolescent population of São Luís. The adjustment of the analysis (multivariate model) to variables such as age, sex, skin color and economic class reduced the possibility of confounding biases. The study's cross-sectional design could be considered a limitation, although it is not an important one because occlusion is established by the age range examined in this study and longitudinal tracking would not change the results significantly.

\section{Conclusions}

Female adolescents seems to be more sensitive to oral health problems. The results suggest that the DAI score might reflect a self-perceived need for orthodontic treatment and the Angle classification might overestimate the orthodontic treatment need.

\section{Acknowledgements}

The authors would like to thank the Universidade Federal do Maranhão - UFMA for providing support through a Scientific Initiative Grant (no. 09/2009) and the Fundação de Amparo à Pesquisa e Desenvolvimento Científico do Maranhão - FAPEMA for supporting the translation of this article. school students: a cross-sectional study. Eur J Orthod. 2005;27(6):601-6. doi:10.1093/ejo/cji043

4. Brasil. Ministério da Saúde. Secretaria de Atenção à Saúde. Secretaria de Vigilância em Saúde. SB Brasil 2010 - Pesquisa Nacional de Saúde Bucal: resultados principais [Internet]. Brasília (DF): Ministério da Saúde; 2012 [cited 2016 Fev 22]. 116 p. Available from: http://bvsms.saude.gov.br/bvs/ publicacoes/pesquisa_nacional_saude_bucal.pdf

5. Marques LS, Barbosa CC, Ramos-Jorge ML, Pordeus IA, Paiva SM. Malocclusion prevalence and orthodontic treatment need in 10-14-year-old schoolchildren in Belo Horizonte, Minas Gerais State, Brazil: a psychosocial focus. Cad Saude Publica. 2005;21(4):1099-106. doi:10.1590/S0102-311X2005000400012 
6. Garbin AJI, Perin PCP, Garbin CAS, Lolli LF. Malocclusion prevalence and comparison between the Angle classification and the Dental Aesthetic Index in scholars in the interior of São Paulo state - Brazil. Dental Press J Orthod. 2010;15(4):94-102. doi:10.1590/S2176-94512010000400014

7. Frazão P, Narvai PC. Socio-environmental factors associated with dental occlusion in adolescents. Am JOrthod Dentofacial Orthop. 2006;129(6):809-16. doi:10.1016/j.ajodo.2004.10.016

8. Oliveira CM, Sheiham A. Orthodontic treatment and its impact on oral health-related quality of life in Brazilian adolescents. J Orthod. 2004;31(1):20-7. doi:10.1179/146531204225011364

9. Farias ACR, Cangussu MCT, Ferreira RFA, Castellucci M. Occlusal characteristics and orthodontic treatment need in black adolescents in Salvador/BA (Brazil): an epidemiologic study using the Dental Aesthetics Index. Dental Press J Orthod. 2013;18(1):34.e1-8. doi:10.1590/S2176-94512013000100010

10. Perillo L, Esposito M, Caprioglio A, Attanasio S, Santini AC, Carotenuto M. Orthodontic treatment need for adolescents in the Campania region: the malocclusion impact on self-concept. Patient Prefer Adherence. 2014 Mar 19;8:353-9. doi:10.2147/PPA.S58971.eCollection 2014

11. Singh V, Hamdan A, Rock P. The perception of dental aesthetics and orthodontic treatment need by 10 - to 11-year-old children. Eur J Orthod. 2012;34(5):646-51. doi:10.1093/ejo/cjr080

12. Nobile CG, Pavia M, Fortunato L, Angelillo IF. Prevalence and factors related to malocclusion and orthodontic treatment need in children and adolescents in Italy. Eur J Public Health. 2007;17(6):637-41. doi:10.1093/eurpub/ckm016

13. Marques LS, Pordeus IA, Ramos-Jorge ML, Filogônio CA, Filogônio CB, Pereira LJ, et al. Factors associated with the desire for orthodontic treatment among Brazilian adolescents and their parents. BMC Oral Health. 2009;9:(1)34. doi:10.1186/1472-6831-9-34

14. Ghijselings I, Brosens V, Willems G, Fieuws S, Clijmans $\mathrm{M}$, Lemiere J. Normative and self-perceived orthodontic treatment need in 11- to 16-year-old children. Eur J Orthod. 2014;36(2):179-85. doi:10.1093/ejo/cjt042

15. Oliveira CM, Sheiham A, Tsakos G, O'Brien KD. Oral health-related quality of life and the IOTN index as predictors of children's perceived needs and acceptance for orthodontic treatment. Br Dent J. 2008;204(7):1-5; discussion 384-5. doi:10.1038/bdj.2008.239

16. World Health Organization. Oral Health Surveys: basic methods. 5th ed. Geneva: WHO; 2013.

17. Instituto Brasileiro de Geografia e Estatística [Internet]. Brasília (DF): IBGE; @2016. Censo 2010: resultados; 2010 [cited 201602 23]. Available from: http://censo2010.ibge.gov.br/ resultados.html

18. Associação Brasileira de Empresas de Pesquisa. Critério padrão de classificação econômica Brasil. São Paulo: ABEP; 2008. Available from: hppt://www.canadapesquisas.com.br/ pastadownload/Critério_Brasil_2008.pdf
19. Angle EH. Classification of malocclusion. Dent Cosmos. 1899;43(3):249-64.

20. Cons NC, Jenny J, Kohout FL. DAI: the Dental Aesthetic Index. Iowa: University of Iowa, College of Dentistry; 1986. $134 \mathrm{p}$.

21. Marques LS, Ramos-Jorge ML, Paiva SM, Pordeus IA. Malocclusion: esthetic impact and quality of life among Brazilian schoolchildren. Am J Orthod Dentofacial Orthop. 2006;129(3):424-7. doi:10.1016/j.ajodo.2005.11.003

22. Tickle M, Kay EJ, Bearn D. Socio-economic status and orthodontic treatment need. Community Dent Oral Epidemiol. 1999;27(6):413-8. doi:10.1111/j.1600-0528.1999.tb02040.x

23. Mandall NA, McCord JF, Blinkhorn AS, Worthington HV, $\mathrm{O}^{\prime}$ Brien KD. Perceived aesthetic impact of malocclusion and oral self-perceptions in 14-15-years-old Asian and Caucasian children in greater Manchester. Eur J Orthod. 2000;22(2):175-83. doi:10.1093/ejo/22.2.175

24. Aikins EA, Dacosta OO, Onyeaso CO, Isiekwe MC. Self-Perception of malocclusion among Nigerian adolescents using the aesthetic component of the IOTN. Open Dent J. 2012;6(1):61-6. doi:10.2174/1874210601206010061

25. Gavric A, Mirceta D, Jakobovic M, Pavlic A, Zrinski MT, Spalj S. Craniodentolfacial characteristics, dental esthetics-related quality of life, and self-esteem. Am J Orthod Dentofacial Orthop. 2015 Jun;147(6):711-8. doi:10.1016/j.ajodo.2015.01.027

26. Claudino D, Traebert J. Malocclusion, dental aesthetic self-perception and quality of life in a 18 to 21 year-old population: a cross section study. BMC Oral Health. 2013;13(1):3. doi:10.1186/1472-6831-13-3

27. Landouzy JM, Sergent Delattre A, Fenart R, Delattre B, Claire J, Biecq M. The tongue: deglutition, orofacial functions and craniofacial growth. Int Orthod. 2009;7(3):227-56. doi:10.1016/S1761-7227(09)73500-4

28. Martins-Júnior PA, Marques LS, Ramos-Jorge ML. Malocclusion: social, functional and emotional influence on children. J Clin Pediatr Dent. 2012;37(1):103-8. doi:10.17796/jcpd.37.1.y75430328427210j

29. O'Brien CO, Benson PE, Marshman Z. Evaluation of a quality of life measure for children with malocclusion. J Orthod. 2007;34(3):185-93. doi:10.1179/146531207225022185

30. Paula DF,Santos NCM,Silva ET, Nunes MF, Leles CR. Psychosocial impact of dental esthetics on quality of life in adolescents. Angle Orthod. 2009;79(6): 1188-93. doi:10.2319/082608-452R.1

31. Gomes AMM, Thomaz EBAF, Alves MTSSB, Silva AAM, Silva RA. Factors associated with use of oral health services: a population-based study in municipalities of the state of Maranhão, Brazil. Cienc Saude Colet. 2014;19(2):629-40. doi:10.1590/1413-81232014192.23252012

32. Silva RG, Kang DS. Prevalence of malocclusion among Latino adolescents. Am J Orthod Dentofacial Orthop. 2001;119(3):313-5. doi:10.1067/mod.2001.110985

33. Thomaz EBAF, Cangussu MCT, Assis AMO. Malocclusion and deleterious oral habits among adolescents in a developing 
area in northeastern Brazil. Braz Oral Res. 2013;27(1):62-9. doi:10.1590/S1806-83242012005000027

34. Bourzgui F, Sebbar M, Hamza M, Lazrak L, Abidine Z, El Quars F. Prevalence of malocclusions and orthodontic treatment need in 8- to 12-year-old schoolchildren in Casablanca, Morocco. Prog Orthod. 2012;13(2):164-72. doi:10.1016/j.pio.2011.09.005

35. Phaphe S, Kallur R, Vaz A, Gajapurada J, Raddy S, Mattigatti $\mathrm{S}$. To determine the prevalence rate of malocclusion among 12 to 14-year-old schoolchildren of urban Indian population (Bagalkot). J Contemp Dent Pract. 2012;13(3):316-21.

36. Huang B, Takahashi K, Yamazaki T, Saito K, Yamori $\mathrm{M}$, Asai $\mathrm{K}$, et al. Assessing anteroposterior basal bone discrepancy with the Dental Aesthetic Index. Angle Orthod. 2013;83(3): 527-32. doi:10.2319/050312-369.1
37. Dawoodbhoy I, Delgado-Angulo EK, Bernabé E. Impact of malocclusion on the quality of life of Saudi children. Angle Orthod. 2013;83(6):1043-8. doi:10.2319/012713-83.1

38. Agou S, Locker D, Streiner DL, Tompson B. Impact of self-esteem on the oral-health-related quality of life of children with malocclusion. Am J Orthod Dentofacial Orthop. 2008;134(4):484-9. doi:10.1016/j.ajodo.2006.11.02

39. Bernabé E, Flores-Mir C. Orthodontic treatment need in Peruvian young adults evaluated through Dental Aesthetic Index. Angle Orthod. 2006;76(3):417-21.

40. Gherunpong S, Tsakos G, Sheiham A. A socio-dental approach to assessing children-se orthodontic needs. Eur J Orthod. 2006;28(4):393-9. doi:10.1093/ejo/cji114 